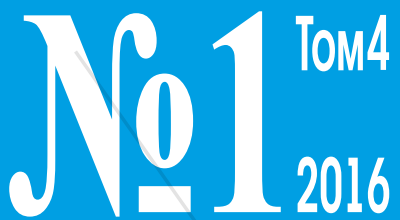

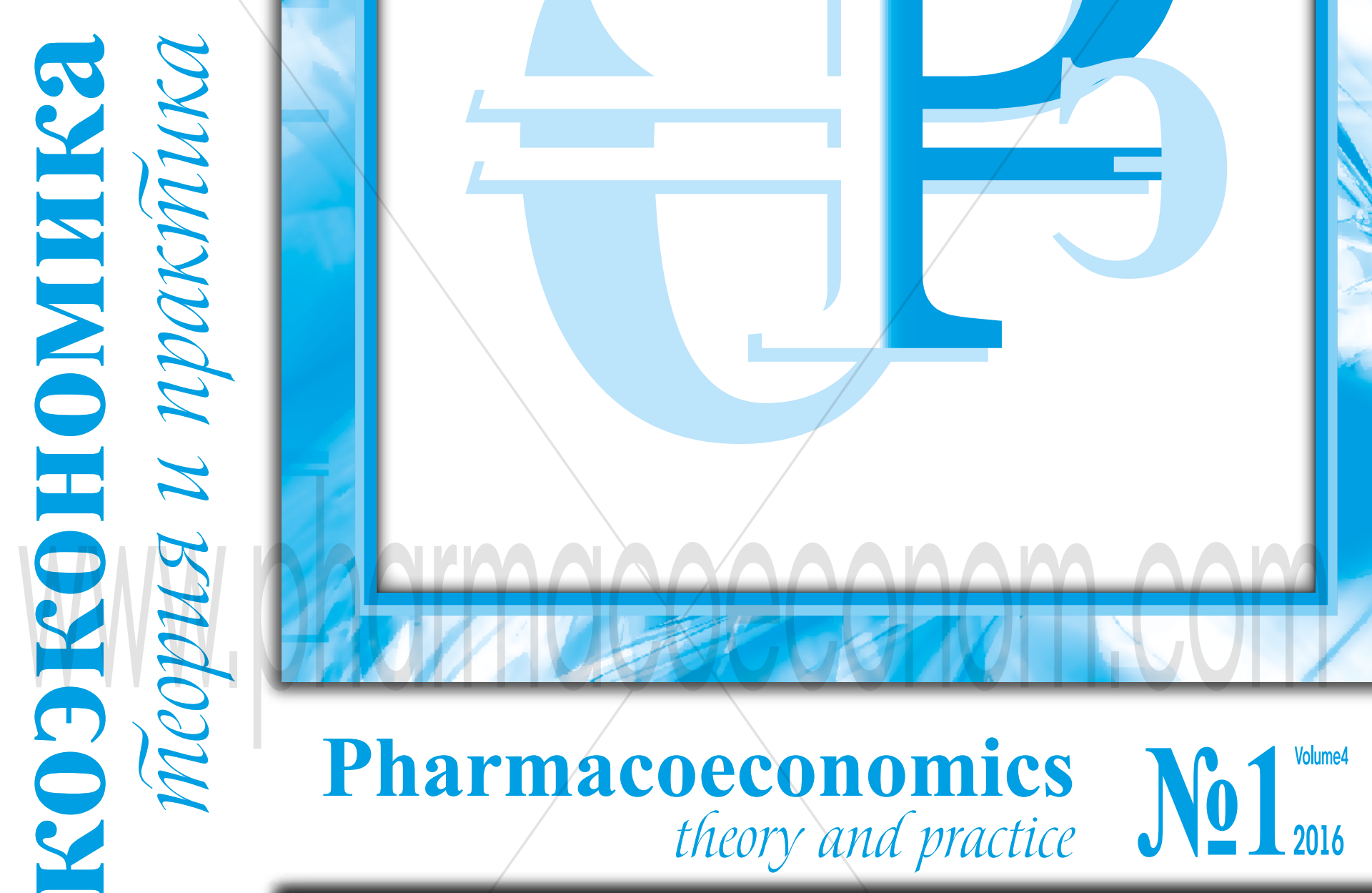

$\square$ МЕТОДОЛОГИЧЕСКИЕ ОСНОВЫ ФАРМАКОЭКОНОМИЧЕСКОГО МОДЕЛИРОВАНИЯ

$\square$ РЕЗУЛЬТАТЫ РОССИЙСКИХ ФАРМАКОЭКОНОМИЧЕСКИХ ИССЛЕДОВАНИЙ

口 МАТЕРИАЛЫ Х НАЦИОНАЛЬНОГО КОНГРЕССА С МЕЖДУНАРОДНЫМ УЧАСТИЕМ «РАЗВИТИЕ ФАРМАКОЭКОНОМИКИ И ФАРМАКОЭПИДЕМИОЛОГИИ В РОССИЙСКОЙ ФЕДЕРАЦИИ» 4-5 апреля 2016 г., г. Нижний Новгород 


\section{ВОЗМОЖНОСТИ КЛИНИКО-ЭКОНОМИЧЕСКОГО АНАЛИЗА В РАБОТЕ КЛИНИЧЕСКОГО ФАРМАКОЛОГА}

\section{POSSIBILITIES OF CLINICO-ECONOMIC ANALYSIS IN WORK OF CLINICAL PHARMACOLOGIST}

Федоренко А.С., Бурбелло А.Т., Покладова М.В., Костицына М.А., Загородникова К.А., Гайковая Л.Б.

Fedorenko A.S., Burbello A.T., Pokladova M.V., Kostitcyna M.A., Zagorodnikova K.A., Gaikovaya L.B.

ФГБОУ ВО Северо-Западный государственныймедииинскийуниверситет им. И.И. Мечникова Минздрава России, Санкт-Петербург

North-Western State Medical University named after I.I. Mechnikov, Saint-Petersburg

Ключевые слова: клинико-экономический анализ, анализ стоимости болезни, стоимость нозологий, клинический фрармаколог.

Введение: ограничения финансирования лечебно-просрилактического учреждения (ЛПУ) ставят перед клиническим фрармакологом задачу экономической оценки медицинской помощи. Недостаточное использование клинико-экономического анализа обусловлено, малой информированностью врачей о данных методах, так и тем, что получаемые величины иногда абстракты и соответственно, результаты не всегда могут быть объяснены администрации ЛПУ.

Цель исследования: определение области применения известных методов клинико-экономического анализа в работе клинического фрармаколога.

\section{Материалы и методы: методы клинико-экономического анализа.}

Результаты: анализ минимизации затрат, в целом не является истинным клинико-экономическим анализом. Метод показывает чистую экономическую выгоду при равной эфффективности схемы лечения или непосредственно лекарственного препарата (ЛП), в связи с чем наиболее понятен администрации ЛПУ. В условиях обычной работы ЛПУ при огромном количестве дженериков вопрос о их терапевтической эквивалентности, и взаимозаменяемости так и не решен.

Анализ «затраты-эфффективность», также имеет ряд ограничений в работе клинического фармаколога. Если расчет затрат не вызывает большого количества вопросов, то расчет критерия эфффективности не всегда однозначен. В рамках ЛПУ и собственно работы клинического фрармаколога, расчет показателя «затраты-эфрфективность» для каждого препарата, при многообразии их воздействия, по разным критериям эффрективности не возможен. В качестве критерия эфрфективности может быть использовано количество неблагоприятных побочных реакций (НПР) при применении ЛП, в результате которых увеличивается длительность пребывания пациента в стационаре и стоимость лечения. Например, развитие антибиотик-ассоциированной диареи. Исходя из этого выбор ЛП с более безопасным профилем и подсчет затрат на дополнительное лечение НПР может стать аргументом для администрации ЛПУ при закупке ЛС. Однако процент регистрируемых НПР, частота неэсрфективности лечения, обусловленная ЛП в одном ЛПУ достаточно низка. Использование литературных данных в этих условиях не корректно и вызывают недоверие, т.к. результаты получаются не конкретными для данного лечебного учреждения. Только четко налаженная система фрармаконадзора в медицинской организации и реальные данные о проценте НПР и неэффрективности ЛС в ЛПУ смогут стать инструментом для использования получаемых данных для клинико-экономического анализа.

Анализ «затраты-полезность» основан на определении затрат на единицу полезности, основным критерием которых являются годы качественной жизни QALY. Анализ должен быть использован системой здравоохранения в целом, тогда как для ЛПУ применение его маловероятно.

В последнее время стали использовать метод «влияние на бюджет». Метод позволяет оценить сумму затрат и экономий сравниваемых технологий и поэтому в отличие от рассмотренного выше метода «затраты-эфффективность», носит количественный, а не качественный характер. Заслуживает внимания анализ стоимости болезни. При проведении анализа стоимости болезни необходимо учитывать все затраты (прямые, непрямые, косвенные). В нашем ЛПУ, клинические фрармакологи по согласованию с администрацией, проводят расчет стоимости не отдельного заболевания, а так называемой стоимости нозологий, при которых применяются сходные методы обследования пациента и ЛП (пример: в гинекологической практике в одну нозологию можно объединить все невоспалительные заболевания женских половых органов; в гастроэнтерологии - кислотозависимые заболевания и т.п.). Такой подход значительно уменьшает объем работы при проведении клинико-экономического анализа и позволяет оценить фринансовые затраты, и риски при оказании медицинской помощи по ОМС.

Заключение: в рамках одноканального финансирования ЛПУ по ОМС и выделения в среднем на расходные материалы и лекарственные средства $13,2 \%$ от тарифа, согласно генеральному тарифрному соглашению, для клинического фрармаколога особо остро встает необходимость проведения клинико-экономического анализа расхода ресурсов на оплату лечения. Использование анализа “стоимость нозологий», позволит уменьшить объем затрат как на лекарственные препараты, так и на расходные материалы при оказании медицинской помощи по системе ОМС и оптимизировать лекарственное обеспечение в ЛПУ. 